\title{
Applying Lean Thinking to Improve Operational Safety in Oil and Gas Industry
}

\author{
Desalegn Yeshitila, Daniel Kitaw, Kassu Jilcha
}

School of Mechanical and Industrial Engineering, Addis Ababa Institute of Technology, Addis Ababa University, Addis Ababa, Ethiopia

Email: jkassu@gmail.com, desuselam@yahoo.co.uk, danielkitaw@yahoo.com

How to cite this paper: Yeshitila, D., Kitaw, D. and Jilcha, K. (2021) Applying Lean Thinking to Improve Operational Safety in Oil and Gas Industry. Open Journal of Safety Science and Technology, 11, 120-141. https://doi.org/10.4236/ojsst.2021.113009

Received: May 7, 2021

Accepted: September 24, 2021

Published: September 27, 2021

Copyright $\odot 2021$ by author(s) and Scientific Research Publishing Inc. This work is licensed under the Creative Commons Attribution International License (CC BY 4.0).

http://creativecommons.org/licenses/by/4.0/

\begin{abstract}
The oil and gas industry with its stringent safety policies, standards, rules and procedures still experience minor-to-major operational accidents/incidents in petroleum exploration and production processes. The root causes of incidents in upstream and downstream sectors are attributed to humans and organizational factors. The sector has been revolutionizing its safety system by way of risk identification and management and hazards hunt at a workplace to reduce the risk level of fatal and non-fatal injuries. In this research, the authors apply lean philosophy to surface the challenges of oil and gas safety system in an innovative way by identifying problems at root source and addressing it with employees' engagement and involvement to continuously improve the safety system. The application of lean thinking has been proven in healthcare and manufacturing industries where this research makes parallel to take advantage of the experiences of the lean founders. Safety should not be a priority as priorities could change based on situations. Instead, safety should be an embedded business value that could be value streamed along the value chain, with value considered from the perspective of customer value that can also include the internal customer, employees. The purpose of this study is to find out why stringent oil and gas safety standards, procedures and rules have not spared the industry from occurrences of occupational accidents and incidents. Therefore, this study aims in addressing how offshore oil and gas exploration and production operational safety can be improved through lean thinking, where upstream work processes are streamlined to improve workplace visibility, eliminate wastes, improve structural sustainability as well as HSE risks and improve operational safety. The study focuses on human side of occupational safety improvement through direct employees' involvement, workforce engagement and lean thinking application using lean philosophy, practice and tools. The study comprises five parts that are: Introduction, literature review, research methodology, result, discussion and conclusion.
\end{abstract}




\section{Keywords}

Operational Incidents and Accidents, Industry Safety Standards, Lean Safety, Employees' Engagement, Waste in Processes, Employee Morale \& Pride

\section{Introduction}

The primary objective of lean thinking is the elimination of wastes. The continuous improvement using waste elimination has been underlined as the most vital task of outstanding organization [1] [2]. The concept was originated from the Toyota Production System [3] [4]. For this, Taiichi Ohno was the first who established efficient work processes. Process wastes [5] need to be identified and continuously removed by optimizing and updating the work process. The eight types of processwastes which need to be eliminated are Defects, Overproduction, Waiting, Not-Utilizing peoples' Talent, Transportation, Inventory, Motion, and Over-processing [6]. These wastes from the context of oil and gas activities are discussed under the results and discussion section.

Researchers from Massachusetts Institute of Technology (MIT) have identified the success behind Toyota's competitive advantage [2] [7] and realized that the company's working culture and management system under the umbrella of TPS were the catalyzing factor that brought the best performance in the automobile industry, and finally coined the production system as Lean production [2]. With the current globalized business environment, easy access to new technology, best working practices and industry-wide procedures are at the exposure of all companies. The competitive edge that would differentiate could be the working culture and the workforce's involvement and engagement.

Gemba walk is the most appropriate method used to identify wastes (Muda) [8]. The Gemba walk is a technique that allows observing different processes occurrences in action and allows observing where wasteful activities appear. The 5 whys and the A3 report are also lean tools, which are used to investigate the root cause analysis and problem-solving. The 5 why's as its name implies comprises five "why" questions [9] while the A3 is a bit more complicated process that encourages cross-organizational knowledge sharing. The conventional way of silo departmentalization and everything designed and dogmatized at the board room could not capture the reality at the shop-floor (Gemba) the real place where the work is done. Thus, multifunctional collaboration and involving the frontline employees should be the way forward in aligning top-down and bottom-up for effective company-wide engagement.

The core philosophy and two pillars of lean thinking are continuous improvement and respect for people [10]. One of the popular lean practices for achieving continuous improvement is through Kaizen event. Kaizen is a Japanese word that translates as "change for better" [11]. The common mistake in business improvement implementation is using buzzwords and applying improvements in a 
campaign kind of mood and lack of sustainability and not building on the small achievements acquired to continuously strive for perfection.

Lean thinking application in automobile industry and healthcare sector has made the methodology popular in product and service provision [12], this is in line with [13] argument to enhance service industry performance through the application of lean thinking. In line with this, this study investigates the application of lean thinking in oil and gas occupational safety application. Safety is not different from any other organizational processes. Therefore, safety needs to be incorporated along the business value stream and any activities that would not add value to the employee's safety, and activities that add hazards to the workforce need to be eliminated.

The Swiss cheese model could be an illustrative model that shows how different factors could contribute to the causations of accident [14] in oil and gas operations. This is also evident in offshore oil and gas activities where there are many factors that jeopardize the safety of the workforces, asset, and the environment in general. Minor faults and negligence could escalate, and the 'dots could join to trigger an accident.

The focus of this study is oil and gas industry upstream sector operation on demanding North Sea offshore sector. The very reason that offshore structures should work under extreme weather conditions, the structural and safety-critical equipment should stay intact and must work properly for the whole part of the life cycle of the installation is due to the demanding working environment and the nature of the product. For any structural design and construction works, it is important to follow standards and codes, guidelines and best practices in order to ensure sustainable structural integrity. Sustainability is also the primary concern in the oil and gas industry [15].

\section{Literature Review}

Every activity has its own risk. Offshore oil and gas activities have various hazards associated with the activities. Oil and gas industry has one of the best industry safety standards and the industry must compliance with the host government stringent regulatory requirements. With all this safety management systems, standards, procedures, rules and regulations the offshore industry is still entertaining from minor to major accidents and incidents. This is in line with [16] argument of the construction industry tragedy that happens every year despite safety programs, OSHA inspections and training, stand-downs, posters and project safety officers. Even if occupational accidents and incidents are known as a major waste in business processes, little consideration has been given so far to integrating safety into the lean management endeavor [17].

Safety management comprises of preparing a plan to ensure that all safety hazards and risks are identified, assessed, analyzed, and then mitigated. This step is associated with lean thinking where business processes are streamlined to eliminate waste and maximize value [18]. Occupational accidents and incidents can 
have negative impacts on cost, schedule, quality, employees' retention, and company reputation and business image. [18] argues that improving workplace safety is a form of waste reduction and value generation. Parallels and interaction between the application of lean thinking and safety management are reasonable because all near misses, incidents and accidents represent waste from the lean perspective [19].

This study focuses on this missing link and capitalizes on the weak-link and drawbacks to bring a different perspective in the endeavor to make the offshore operations incident and accident free working environment through continuous safety improvement. Lean is a people-based management system with high workforce engagement and Involvement. Lean methods involve continuous process improvement through the systematic elimination of waste, prevention of mistakes, and empowerment of employees to make changes in their everyday work. The frontline employees' hands-on experience makes them the one to suggest safety focused improvement ideas at the same time adding value for the customer.

Lean thinking take advantage of frontline employees capability development (coaching and mentoring) and empowerment (autonomy and trust building and allowing the employees to do the job and improve it at the same time) this has positive effect in employees moral and job satisfaction, strategy buy-in and in the same way promote occupational safety [20], not giving proper valueto occupational safety and process hazards impact on productivity and employees' well-being [21].

Lean has various tools that could also apply for oil and gas safety context. For example, $5 \mathrm{~S}$ brings a work environment that is clean and tidy with good housekeeping that helps to aid visual management and helps to see problems easily. $5 \mathrm{~S}$ is a commonly used Lean tool that focuses on creating an organized work environment [22]. Mistake-proofing or Poko-Yoke is a lean tool to fail safe and protect damage to assets and workforce in cases of process failure, PDCA continuous feedback and improvement etc. [23].

Lean thinking and its tools are known for benefits such as less process waste, reduced lead time, less rework, reduced inventory, increased team morale, best warehouse organization, elimination of unused tools, reduced time in travel to search for material and tools [24]. Moreover, arguably lean tools could be used to reduce incident and accident rate at the workplace. For example, $5 \mathrm{~S}$ keeps the working environment tidy and clean. $6 \mathrm{~S}$ (5S+ Safety) is the application of $5 \mathrm{~S}$ to enhance safe working environment. In a clean and organized environment, it would be easy to see hazards and avoid employee's injury. A $6 \mathrm{~S}$ practice is more than just a clean and tidy workplace, it is a way of warranting organization and standardization to clearly see errors while happening into the day to day way of doing things [25].

The oil and gas industry upstream offshore sector are a risky business. The sector operates in extreme environment and the nature of the product, Hydro- 
carbon needs extra caution in exploration, handling and transportation. Consequently, it is important to develop substantial safety measures for lowering risks and safeguarding workforces and assets. With all stringent industry safety standard and procedures, the current safety state of the sector still shows encountering from minor to major accidents and incidents. [26] [27] argue that Lean applications have the potential to improve safety standards and enhance safety performance. In the current business environment good safety performance is a competitive advantage that could give firms to win the competition and acquire the support for the general stakeholders.

Based on best practices and international standards, the NORSOK D10 standards is designed for well and operation to be applied in the North Sea continental shelf. The paper mainly uses NORSOK D10 standard (Well integrity in drilling and well operations).

NORSOK D10 defines well integrity as the application of three solutions with the objective of reducing the risk level of undesired leak during the life of the well, which increase the maximum productivity of the reservoir as well as avoid loss of natural resources and maintain safe environment, NORSOK D10. The solution is technical, which deals with design and material selection. The second solution is operational monitoring, which includes inspection, maintenance and integrity pressure testing. The third solution is organizational, it is all about competence, training as well as proper data handing and transfer. However, occupational injuries and accidents as well as environmental degradation issues reported during petroleum works lacks consistency [28]. Standards alone could not bridge the gap in safety management that is why the authors of this paper argue to do more than compliance to standards, legislations and regulations by actively engaging the frontline workers in continuous safety improvement.

Figure 1 shows a typical best practice guidance for offshore lifecycle operations, which includes exploration, development, production and decommissioning phases [29]. More detail activities with regards to operational phases both testing, and acceptance criteria are documented in NORSOK D-10. However, the process requires a continuous follow-up, inspection, remedial actions as well as updating the standards are the key to prolong the lifetime of the well, extract efficient amount of energy with cost effective investment, and improve HSE as well. For instance, during decommissioning phases, the operation investment is without return value. However, a continuous technological and innovative methods as well as reliable standards which suits best for this operation can reduce the operational costs of Plug and abandonment ( $\mathrm{P} \& \mathrm{~A}$ ) and improve long term integrity, which is a key factor for safe environment.

Due to ever increasing energy demands, the oil and gas industry activities are expanding to deep-water and arctic regions, which are operationally challenging environments. The technological development and performance in the oil and gas industry is continuously improving. For instance, the 1990-2005 inventory result obtained from several European O\&G wells showed that the drilling rate 


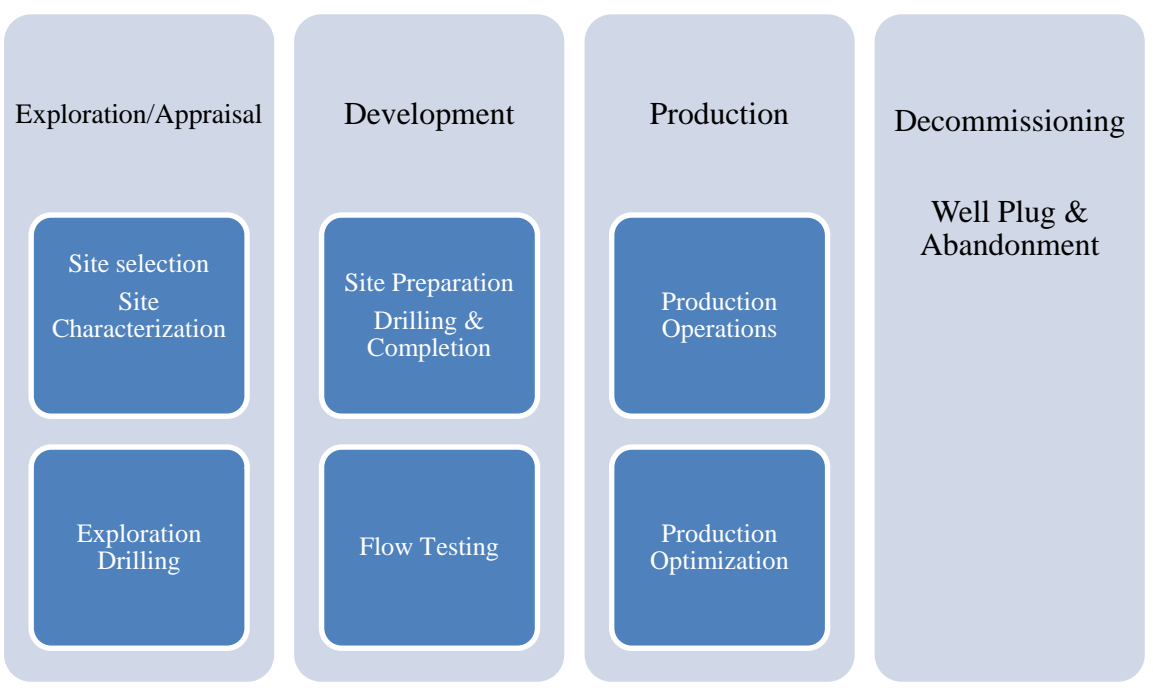

Figure 1. Offshore lifecycle and activities; source: Best Available Techniques Guidance Document on upstream hydrocarbon exploration and production [29].

per day is increasing. However, the non-productive time is flat, is approximately 25\% throughout the years [30]. The year 1993-2003 NPT in the Gulf of Mexico was about $40 \%$ [31]. Since drilling rig rate is expensive, the visible and non-visible nonproductive times cost the oil industry a lot. The root cause of the NPT (nonproductive time) is associated with among others kick, lost circulation, stuck pipe, drill string failures, waiting for supplies, waiting on weather, waiting on service providers fixing problems, waiting on safety related incidents and accidents and wellbore instability.

One of oil and gas well hazardous situation is Kick; Kick is an influx of hydrocarbon to the wellbore. It occurs when the well pressure is lower than the reservoir pressure. Controlling kick with properly designed control procedures prevents from undesired surface blowout. For instance, in 1988, the Piper alpha blow out incidence in the North Sea costed 167 workers lives and several of serious injuries as well as cost billions of dollars [32]. In 2010, the Deep-water Horizon blowout incident in the Gulf Mexico resulted in the largest oil spill in the oil and gas industry [33]. The accident costed 11 human life, environmental pollution, and loss of huge resources as shown in Figure 2. The root cause of the incident was due to eight essential technical problems. Investigators indicated the operational gap between BP's operation with respect to NORSOK D-010 and API standards. This indicates the need to continuously improve guidelines based on best practices [34].

[36] indicated that humans and organizations are the key factor for safety of offshore/onshore structures engineering works such as design, construction, operation, maintenance, and decommissioning phases. Human factor involved with a continuous real-time management of safety during operations, and development of an appropriate Safety Management Assessment System prolong the life of the structures [36]. 

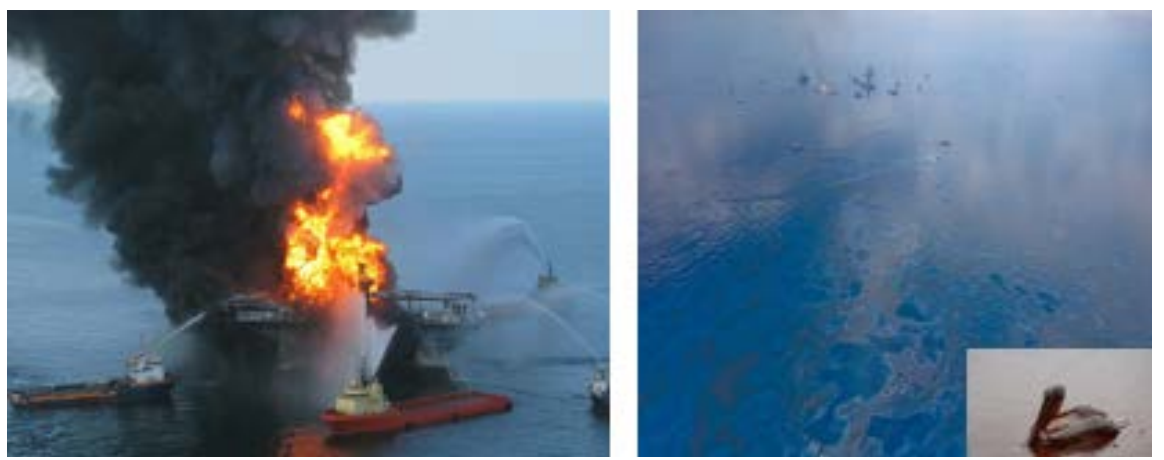

Figure 2. Blowout and its consequences Macondo [35].

According to [37] the accident in the Piper Alfa attributed to human and organization factors were involving hazardous technology failures, which includes poor design guidelines and design practices, mistakes in the management of the personnel on board vs. safety, and as well as errors in decision/action, and insufficient attention to inspection and maintenance operations.

Structural integrity of platforms and drilling rigs might be worsening due to physical damages such as corrosion and mechanical impacts as well. Implementing Safety Management Assessment System would reduce the risk of structural failure and accidents, which as a result reduces NPT wastes related with maintenance and undesired expenditure. [38] argue that Oil and Gas (O\&G) platforms in the North Sea are facing aging problems as many of the installations have matured and are approaching their design lifetime. The authors considered Flow line degradation due to corrosion and erosion to exemplify their argument. The deterioration of a flow line may increase the risk of leakages, ruptures, etc., which shall lead to serious HSE (health, safety and environmental) and financial consequences.

As exemplified earlier, the occupational injuries and accidents as well as environmental degradation have occurred during petroleum works. This occurs in the upstream (exploration and production sector) and downstream (petrochemical industries) as well. The main important issue to be addressed in this paper is therefore how to minimize the risk factor of offshore installation, well integrity, at risk behavior, and generally risks during drilling and production throughout the life cycle of the operation. The risk is expressed risk to assets, environment and people.

Therefore the purpose of this study is to explore the upstream oil and gas industry standards and regulatory body procedures, rules and requirement that serve as a foundation to practice safe oil and gas operations and further analyze the perspective in which to perform the activities seamlessly with continuous safety improvement culture.

\subsection{Lean Thinking}

Currently the oil and gas industry is working to develop methods and technologies in order to improve operation performance, minimize HSE (Health, Safety 
and Environmental) risks, reduces non-productive time, enhance productivity and hence minimize operational costs [39]. With the current volatile oil price, the industry needs to eliminate non-value adding activities to stay competitive and offset the low margin.

Well construction is like manufacturing car, which use a set of predesigned workflow processes in order to achieve the desired final product. In the recent years, the application of Lean thinking in manufacturing and auto industry and health care have shown impressive result in a sense of process waste management as well as effective performances, and problem solving and customer value addition. This paper, therefore, will look at the application of lean philosophy in triple bottom-line improvement in the area of economic, environmental, safety and social benefits in the oil and gas industry, with specific focus in offshore drilling and production sector [40].

Hazards are everywhere at the workplace. In most cases it is not possible to eliminate work hazards totally, but one could use hazard control mechanisms. There should be effective hazard identification method in place to identify the Hazards for every activity and implement hazard control mechanisms. Some oil and gas companies have a practice of Hazard hunting where employees in group go out to the workplace and hunt for potential hazards.

Figure 3 as it is proposed by: National Institute for Occupational Safety and Health [41], hierarchy of hazards controlled listed from the most effective to least effective.

Accidents happen due to unsafe act and unsafe conditions. Most accidents and injuries originating from workplaces are attributed to employees' unsafe act [42]. Oil field platforms and Rigs offshore need to endure the extreme weather conditions to stay intact for the lifecycle of the installation.

\subsection{The Eight Types of Waste in Oil \& Gas Wells Production and Exploration}

In Lean management, the eight wastes (Muda) are the basic concepts, which need to be identified in order to optimize resources and increase profitability. The oil and gas industry have been in downturn where profit margins are ever diminished and various costs surges time to time and access to new reserves are becoming a challenge. [43] Pointed that conventional oil and gas well delivery, on average accounts for 40 percent to 50 percent of the capital spending for exploration and production. Thus, it is imperative to streamline the oil and gas exploration and production processes to minimize and eliminate non-value adding processes wastes. Figure 4 displays the categories of wastes by activities:

Drilling exploration, development injection well $42 \%$, run casing and liner, pump cement, pressure testing 3\%, rig up, rig down, tripping, lay down pipes $22 \%$, wait time $5 \%$, defect repair, maintenance, circulating $13 \%$, transportation rig move skid $3 \%$, compliance on process best practice such as wait on cement, $9 \%$, other $3 \%$ [44]. 


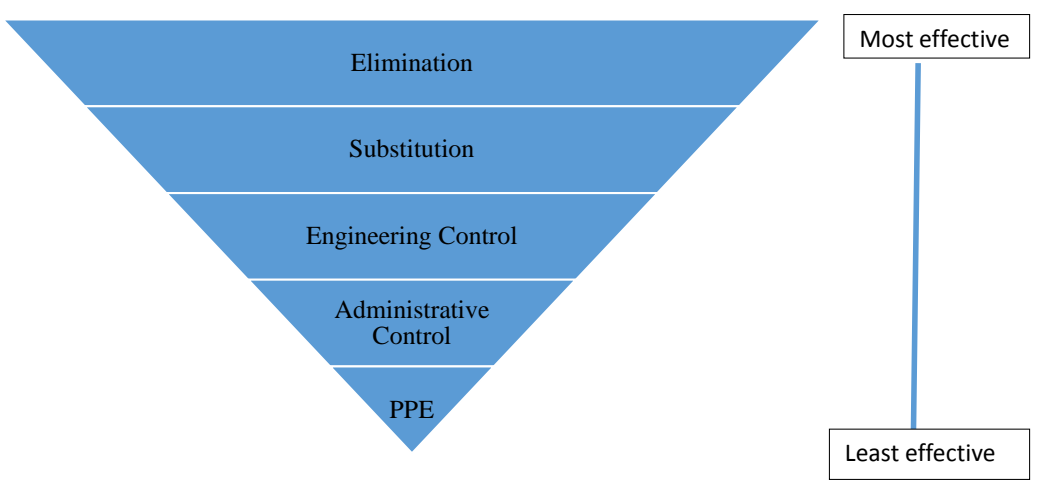

Figure 3. Hierarchy of hazard control [41].

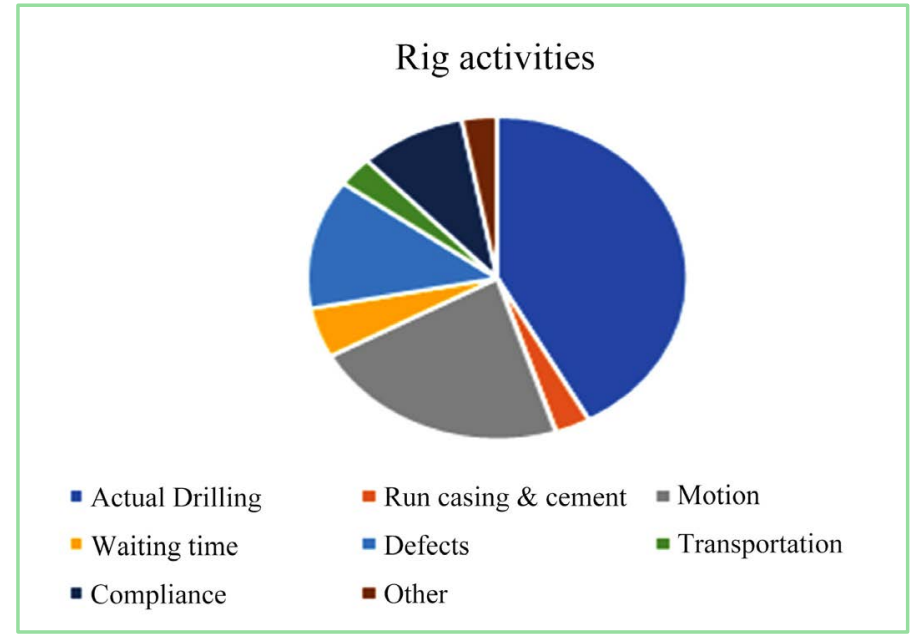

Figure 4. Break down of rig activities categorized by waste [44].

\subsection{Offshore Oil and Gas Well Integrity and Safety}

Petroleum business is capital and technology intensive and high-risk business. Once petroleum accumulation is discovered, it is important to design production installation that has longer life to exploit the resource in order to be economically profitable, environmentally friendly and socially responsible and doing all these with focus on employees and asset safety.

Reliable well integrity system is a crucial element in all life cycle phases of a petroleum activity to secure safety of employees', assets and the general environment [45]. For instance, the well integrity survey conducted on Norwegian continental shelf (NCS) shows that out of 75 production and injection wells, $39 \%$ records tubing failure and $11 \%$ cement and casing each. Moreover, $5 \%$ exhibited packer failure [46].

As part of the well integrity, NORSOK D10 requirement, during operational phase, the standard demands to conduct pressure testing. Hence the pressure testing resulted in the production casing collapse, which leads to the production tubing collapse. Investigators found out that during engineering design works, the engineers wrongly selected a casing which is $30 \%$ lower in strength than what was supposed to be used [47]. 


\subsection{Gaps Identified}

This research has identified some important gaps and points not covered in most of safety related articles published in main-stream journals. Here are some of the gaps pinpointed:

1) Taking safety measures as an obligation and a must do approach instead of educating employees to take safety measures as values intentionally incorporated in the work system for the benefits and advantages of the employees.

2) Focusing on major accidents and giving less emphasis on near-misses and minor incidents and not reporting and recording such incidents and communicating clearly company-wide to learn from them.

3) Not taking safety as part of the overall process in the company system, trying to tackle safety as one-time endeavor and flavor of the month on a campaign level. Contrary to this lean thinking considers system approach and tackling problem along the value chain using value stream mapping approach to identify activities in the process that does not add value safety is not different. Lean approach advocates people are not the cause of problems rather the broken process is the cause of problem, not different for safety as a process.

4) Safety system approach based on safety staff and frontline employees without top management involvement. Safety is everybody's responsibility. Lean approach bases any improvement on respect for people philosophy. Thus, the employee is the one doing the job and at the same time improves the work process and this includes safety as part of the process.

5) Compliance based safety approach. Even if compliance is the starting point for safety and foundation and basic requirement compliance is not quite enough by itself to prevent accidents and incidents. People based approach and continuous improvement in safety is beyond regulatory control approach to safety where employees go beyond compliance to exert discretionary efforts.

\section{Research Methodology}

For this purpose, high impact factor academic research journals were reviewed to review the current state safety practice in oil and gas industry. Some of the academic research sources searched were: Science direct, Springer, Emerald, web of science, Elsevier etc. The key words and phrases used in search were lean safety, occupational safety, employee engagement, workplace safety, 5S, workplace visibility, employee involvement, safety leadership, error proofing, and 5 why, etc. characteristics.

The research methodology followed for this paper was, perspective research, where it started from problem definition to final, conclusion and conceptual model development. The process starts with objectives setting, identification (searching) of relevant articles from various database based on search word and phrases mentioned on methodology, screening of articles relevant to set objectives, obtaining appropriate articles, gap identification, developing conceptual framework and finally draw conclusion. 
Oil and Gas industry has one of the best industries safety standards, procedures and safety practices. Moreover, host countries where the international and national oil companies operate require companies to comply with stringent government regulations and safety standards. With all these safety management and standards and procedures in place, we still experience from minor to major accidents and incidents in the industry. This study asks one important question, what is missing in the system as the slogan goes in the industry "Zero incident and accident" never been achieved. The authors of this paper argue that the important thing that has been missed from the equation is employee's engagement and involvement in the general safety management system. Thus, this paper basis its argument on one of the core pillars of lean philosophy, "respect for people" as it positively impacts occupational safety in oil and gas industry.

\section{Result and Discussion}

This section of the paper discusses the lean thinking application for oil and gas safety enhancement.

The eight wastes are discussed here as it applies for oil and gas upstream operations. Each kind of process wastes from offshore drilling and production perspectives.

Transportation: Among the challenges in upstream offshore oil and gas activities is the difficulty of supplying various supplies for the offshore activities. The remoteness and harsh weather condition make it daunting task to deliver supplies without delays.

In lean thinking transportation is among the seven wastes. The longer the time spent on transportation the higher will be the total cost. Thus, it is in the best interest of the overall business value chain to reduce transportation time as this from the perspective of lean thinking does not add value. Supply chain visibility and integrated drilling approach and collaboration of players along the value chain is best practice in reducing delays in equipment and material supplies and in reducing total costs.

Inventory: Offshore remote exploration and production have imposed various challenges for oil and gas industry [48]. One of these challenges is to supply offshore drilling and production installations continuously with workforces, and food. Some of the inventory items in conventional drilling processes are: drill pipes, drill bits, drill collars, heavy weight drill pipes and collars, casings, liners, drilling fluid, cement, barite, lost circulation materials, various chemicals, spare parts and accessories for Mud Pumps, blow out preventers, drill line, motors, engines, valves, surface equipment, living quarter related food items and other related stuffs. Helicopters and special vessels are used as means of supplying items. In lean thinking inventory wastes is among the wastes. The inventory holding cost and limitation and shortage of space in offshore drilling installation further complicates the matter.

Motion: Motion wastes are unnecessary movement by people working the 
job. A working environment design using the science of Ergonomics and lean work process streamlining would minimize nonvalue adding employee motions and reduce risk and negative impact on the health of employees that could be caused by poor working environment design. Unnecessary movement of people for obtaining information by walking up and down the rig deck, travelling to redundant meetings etc. are how motion wastes are articulated.

Waiting: Waiting is one of the most frequently happening waste in offshore oil and gas drilling; where there could be: waiting on order, waiting on service company crew and equipment, lost circulation, fishing, work on stuck pipe, mud conditioning, waiting on weather, rig repair. Waiting for goods to be delivered, incur huge cost components in well delivery are attributed to the rig rate and service and equipment rentals. These components are both time-dependent and a function of prevailing service market demand. The conventional offshore drilling is performed as sequential activity where one phase of an activity is finished to start the next operation. For example, in a nutshell there are the main sequential activities: drilling-wire line-casing-cementing, etc. Moreover, waiting could happen while waiting for decision and further information from town, on how to proceed on some critical issues.

Overproduction: Lean practitioners consider overproduction as the "deadliest" waste of all as causes other wastes, such as inventory, defect, transportation, motion, etc. In offshore oil and gas drilling context, overproduction could be expressed in forms of producing more information than needed. One of the visible overproductions in offshore drilling is various players in the value chain producing the same deliverables and weakly collaborated players in various service value chains. Another instance on overproduction is where offshore employees are asked to daily report the same safety observation stop card to various parties.

Over-processing: Over-processing exemplified in forms of processing information beyond the requirement, over-engineering. In offshore drilling context over processing could be revealed as long meetings, too many email exchanges, reworks due to change of deliverables, etc.

Defects: Most of the North-Sea offshore oil and gas installation are aging and liable for defects due to corrosion and material fatigue. Defects and rework lead to unnecessary effort and misappropriation of resources which otherwise could have been invested in value adding activities. In oil and gas projects' environments where several activities are undertaken concurrently, rework can occur from errors, omissions, failures, damage, and change orders [49].

Unutilized employees' talent: People are the most important assets of an organization that make or break the success of an organization and giving it a competitive edge. Not utilizing employees' talent and capability to do the job and at the same time to improve it continuously is the wastes of all [1] [50].

\subsection{Lean in Upstream Oil \& Gas Sector}

Lean drilling applies the principles and imbedded cultural philosophy of lean 
manufacturing in all activities and phases of drilling, completion and production processes. The process streamlines all activities by passing the conventional silo functions.

Table 1 summarizes some of the application of lean in manufacturing and drilling engineering. The National Institute of Standards and Technology (NIST) Manufacturing Extension Partnership surveyed forty of their clients who had implemented Lean Manufacturing [51]. The survey results showed that the lean manufacturing reduced (time, work in process inventory and space utilization), increased productivity and quality significantly.

According to [52] properly applied lean drilling could bring performance improvement including halving of time used, $30 \%$ cost reduction. Studies indicated that the application of lean on the rig movement and well planning cycle improved by $30 \%-50 \%$ and $40 \%-50 \%$ respectively [44]. This illustrates the huge potential of lean application in the upstream and downstream sectors. This is illustrated in Table 1 below.

\subsection{Lean HSE}

HSE management system is a tool to control and improve the performance of health and safety and environment in all development programs of industrial and other structural organizations. This is in fact an integrated system, so that all human financial and equipment resources will support each other to provide a healthy and convenience environment with no any accident and injuries [53].

Table 1. Application of lean thinking in manufacturing and drilling engineering works.

\begin{tabular}{|c|c|c|c|}
\hline Operation & Method & Improvement & Authors \\
\hline \multicolumn{4}{|c|}{ Drilling } \\
\hline Rig movement & Lean drilling & $30 \%$ & {$[44]$} \\
\hline Rig move cycle & Lean drilling & $30 \%-50 \%$ & {$[44]$} \\
\hline $\begin{array}{l}\text { Well planning } \\
\text { cycle time from } \\
\text { well concept to spud }\end{array}$ & Lean drilling & $40 \%-50 \%$ & {$[44]$} \\
\hline \multicolumn{4}{|c|}{ Manufacturing } \\
\hline Lead time reduced & $\begin{array}{c}\text { Lean } \\
\text { Manufacturing }\end{array}$ & $90 \%$ & $\begin{array}{l}{[51] ;} \\
{[31]}\end{array}$ \\
\hline Productivity increased & $\begin{array}{c}\text { Lean } \\
\text { Manufacturing }\end{array}$ & $50 \%$ & $\begin{array}{l}{[51] ;} \\
{[7] ;} \\
{[31]}\end{array}$ \\
\hline $\begin{array}{l}\text { Work in process } \\
\text { inventory reduced }\end{array}$ & $\begin{array}{c}\text { Lean } \\
\text { Manufacturing }\end{array}$ & $80 \%$ & $\begin{array}{l}{[51] ;} \\
{[31]}\end{array}$ \\
\hline Quality improved & $\begin{array}{c}\text { Lean } \\
\text { Manufacturing }\end{array}$ & $80 \%$ & $\begin{array}{c}{[51] ;} \\
{[7]}\end{array}$ \\
\hline Space utilization reduced & $\begin{array}{c}\text { Lean } \\
\text { Manufacturing }\end{array}$ & $75 \%$ & {$[51]$} \\
\hline
\end{tabular}


The oil and gas offshore activity is one of the high-risk industries. Thus, the sector gives high emphasis for continual improvement in HSE performance. Developing an HSE culture is a collaborative endeavor that requires involvement of all concerned players [54].

The two core pillars of lean philosophy are respect for people and continuous improvement. Lean HSE basis its foundation on this philosophy, where HSE performance cultures are promoted by workforce engagement and involvement, instead of the traditional approach of HSE compliance and Top down policy procedures without the front-line employees' involvement.

Following an established operational procedure with understanding and applying correctly will reduces the risk of HSE. However, according to the lean thinking, since operations and operational areas becoming complex, the standards and best practices should be continuously be updated and employee needs to be trained regularly. It is also important to ensure that the identified risks are understood in order to take a correct measure. During operation, correct radio communication is vital, which reduces the risk of misunderstanding and doing the job in more understandable and effective manner. All these are basically relying on the efficient training program, which is essential personnel on identified equipment and operations as well as identify operational limitations due to wind, rig heave etc. Moreover, follow operational requirements to prevent falling objects in order to secure tools and materials to prevent them from falling on people below. The use Barricade hazard areas and post warning signs use toe boards, screens on guardrails or scaffolds help to prevent falling objects.

It is important to ensure quality handover for all personnel during shift changes Perform the work without injuries to personnel, environmental impact or damage to equipment used and installed. HSE culture development is not a one moment endeavor. It needs a continuous learning, problem solving and experimentation using scientific problem-solving method, such as PDCA A3, root cause analysis, 5 why, 5S, error proofing, Gemba walk, etc.

Demands on the petroleum industry are driving continual improvement of health, safety, and environment (HSE) performance. It has become widely recognized that the deliberate and structured creation of HSE culture directly affects HSE performance. Developing HSE culture is a complex recipe that combines values, leadership, management systems and processes, behavioral and cognitive psychology, technology, equipment, and HSE expertise. This combination creates a safety culture or, way of working in the organization.

\subsection{Lean Operational Safety}

Safety is a critical issue in the oil and gas industry. The oil and gas industries use a great number of standards and guidelines. The use of these standards enhances technical integrity, improves safety, reduces environmental damage, and promotes business efficiencies that result in reduced costs. On the other hand, poorly designed well engineering works may ended up with structural failure 
and results structural catastrophe, cause human life and as well as negative impact on the environment and resources as observed in the North Sea (1988) Piper Alfa platform, Gulf of Mexico deep-water horizon.

It is common practice to perform risk assessment for all well operations. As performing the risk assessment for a given operation such as system installation/construction procedures, it is important to identify any risks associated to the system that has a safety and environmental impacts [55] [56].

Lean thinking is not all about the application of lean tools, which is customary by some lean practicing companies. Lean thinking is a cultural mindset whereby organizations pursue continuous improvement by combining the human side of lean, respect for people. Lean thinking is an all rounded philosophy that focuses on process waste elimination, customer value innovation, smooth process flow, employee engagement and involvement, problem solving, knowledge sharing, open communication and continuous improvement collaborating all stakeholders. Some of the lean tools that could promote working environment safety, employees' ergonomics and value stream visibility are:

1) Five S's (Sort; Set in order; Shine; Standardize; and Sustain). By using this lean tool organization could maintain a working environment that is visible along the value chain, and people could easily see problems, unsafe process line and defects before it could result hazardous situations that may lead to incidents, near miss and accidents. Emphasis has also been laid down to use $5 \mathrm{~S}$ as a workplace organization method which maximize efficiency and effectiveness by identifying and storing the items used, maintaining the area and items, and sustaining the new order. In a clean and tidy work environment it would be easy to see problems exposed.

2) Error proofing, "Poka yoke" in Japanese, is a lean tool that helps in preventing human error by disabling a system not to function in case of operator error. This is one of practical tools that could to be implemented in a process line to stop a process when it is deemed unsafe. For example, a washing machine could not start when the machine door is open (Shigeo Shingo).

3) "Plan, do, check, act" (PDCA): Iterative model, continuous process of business improvement method where processes are iteratively done to identify problems and take countermeasures and measure the performance and keep the cycle continuously for continuous improvement [57].

4) Five whys: is an iterative problem-solving method where one uses to ask why until reaching to discover the root cause of the problem. This has an important implication in working environment safety where it helps to fix the root cause of the problem that could be source of accident. When analyzing a problem there are two root causes to be identified: a) Why the defect was made; and b) Why the defect was not detected (at the point of cause). The 5 Why process, but more importantly, the "thinking way" is an effective yet simple and flexible method to deliver robust results and help ensure that you resolve problems quickly and effectively. 
5) Production leveling, Japanese Heijunka, is a process of leveling production to reduce Mura (unevenness) in production that could result in Muri (overburden) that could wear away machines, equipment, even workforces that operate the system.

The above-mentioned lean tools are just few examples that could be applied in promoting working environment safety culture. It is imperative to note that any tool, techniques and best practices bring fruit whenever it gets buy-in from the workforce and employees' full engagement.

The oil and gas industry are currently moving to digitization and automating operations. It is evident that carefully designed workflow would contribute a lot for an efficient and optimized operations. For this, an appropriate experience and expertise are the key for interpreting if incase an incident alarm detected. This will greatly help in terms of moving ahead or to conduct a quick remedial action. Among others, Error proofing, "Poka-yoke" in Japanese, is a lean tool that helps in preventing human error by disabling a system not to function in case of operator error. This is one of practical tools that could to be implemented in a process line to stop a process when it is deemed unsafe.

The common believe by lean practitioners is that the main cause of process wastes are broken processes. Thus, process waste elimination and employee involvement in continuous process improvement would positively improve the working environment safety culture. When it comes to safety, the authors found it exemplery to refer to the experience of the leading oil and gas operator on Norwegian continental shelf (NCS). Equinor Safety standard under the umberella of "I am safety" is a personal engagement and responsibility for safety is the foundation for Equinor safety clulture.

From Northsea offshore day to day activities the most common personal incident and accidents are hand injury. Bone fracture was the most frequent reportable accident followed by strains and lacerations, Figure 5 (Reportable injuries by type).

Based on the oil and gas industry injury reports the authors of this paper has developed a conceptual model focusing on one of the most frequent injuries, hand injury. The abbrevation HAND has been used as a metaphor to aware each and every employee to focus on the task at hand with high attention. HAND stands for: $\mathrm{H}=$ Hazard, $\mathrm{A}=$ Awarness, $\mathrm{N}=$ Neutralization, $\mathrm{D}=$ Delibration. Thus this is a contionous cycle of focusing on task, by follwing steps of: Hazard assessment and awarness of the danger and neutralizing it and doing the task with deliberation. Thus with this simple rule one would evaluate the hazard to the precious body part hand before we extend our hand to the hazard and danger.

As identified in the literature gap part near-misses and minor injuries are usually overlooked and escaped and left unreported. Nevertheless, whatever small the near-miss or injury level open communication and learning from the incident and improving the process towards value addition to contribute positively to the employee safety need to be organization culture. As safety is a paradigm shift in organizational culture than a onetime program (Figure 6). 


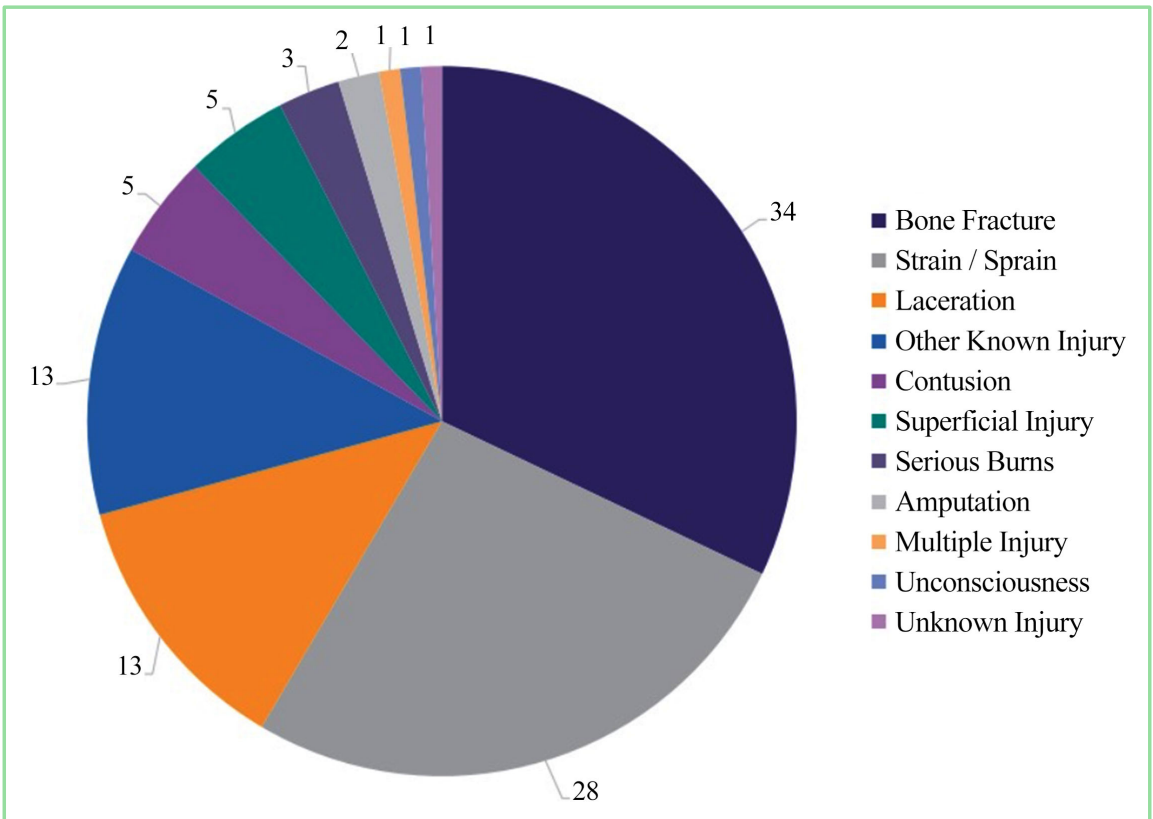

Figure 5. Reportable injuries by type [57].

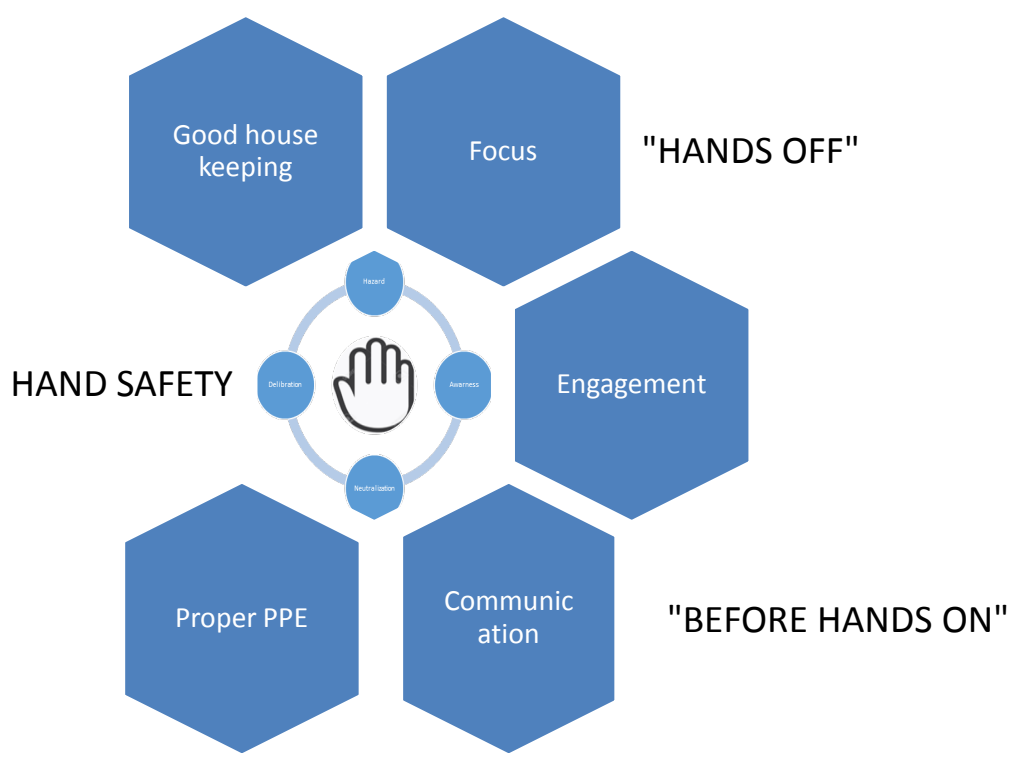

Figure 6. Conceptual model for HAND injury awareness (Authors perspective).

\section{Conclusions}

The contemporary corporate firms sustainability expressed in terms of social, economic, environmental and safety aspects is becoming the norm. The globalized business environment has given business to access technology, information and other important resources almost equally. Thus, the differentiating factor in competition is how each of these firms uses their workforce's talent, creativity and gets them involved and engaged in a strategic way and how businesses focus on customers' value and continuously innovating business processes.

Offshore oil and gas exploration and production activities by its very nature 
have a high impact on the environment, local community, workforce and ecosystem in general, and consequence of accident on an organization in particular. Thus, developing accident-free working environment is in the best interest of an organization to pursue business sustainably and acquire the consent of the interest groups (government regulatory body, environmental group, local community, workers union, other industries such as fishing, etc.).

Work environment safety from the context of offshore oil and gas drilling and production is a result of workforce safety culture, offshore installations integrity, company HSE best practices, regulatory body standards, safety management systems, organizational problem-solving culture, employee engagement and involvement, and continuous HSE improvement culture, collaboration of all players along the value chain.

Command and controlling safety measures as if it was against the interest of the employees, sends a wrong message as if safety measures are not in line with employees' interest. Safety measures need to value the well-being of the employees and should be leveraged as a common interest to build trust between employees and top management.

Focusing on major accidents and giving less emphasis on near-misses and minor incidents and not reporting and recording such incidents and communicating clearly company-wide to learn from them led to missing the root causes of accidents and missing how events develop to cause extensive accident.

Safety system is part of the overall organization system imbedded in every process. One of the common mistakes in safety management is attempting to tackle safety as a one-time endeavor and flavor of the month on non-continuous campaign approach basis. Contrary to this lean thinking considers system approach and tackling problem along the value chain using value stream mapping approach to identify activities in the process that does not add value safety is not different. Lean approach advocates people are not the cause of problems rather the broken process is the cause of problem, not different for safety as a process.

Safety system problem-solving method need to be bottom-up and up-down. Using Safety staff and frontline employees alone without top management involvement does not bear the envisioned fruit. Safety is everybody's responsibility. Lean approach centers any improvement on respect for people philosophy. Thus, the employee is the one doing the job and at the same time improves the work process and this includes safety as part of the process.

Compliance is the foundation and the minimum requirement in safety management. Hence, Compliance by itself is not quite enough to prevent accidents and incidents. People-based approach and continuous improvement in safety are beyond regulatory control approach to safety where employees go beyond compliance to exert discretionary efforts.

Thus, this study suggests that the lean philosophy that centers on employees' engagement, workforces' involvement, cross-functional collaboration, committed leadership is the one complementing the safety system of standards, proce- 
dures, policies and regulations. Lean is a people system; people are the key factors to break or realize safety system at work environment to keep themselves and others around. Hence, lean thinking-based safety system is people-based safety system that would give the individual employee to focus on the task at hand with the right to stop the work in case of doubt and unsafe act and unsafe conditions.

The overall results of effective lean thinking implementation are improvement in productivity, minimize cost and reduction of non-productive time, and reduce waiting related to incidents and accidents. The authors of this study argue that there is a missing factor in the equation of offshore oil and gas activities. With all due respect for standards, procedures, regulations and policies, the human side of the equation has been given less weight and emphasis. As it is customary in lean thinking practices, the key secrets of outstanding organization could be the foundation of the organization on one of the two pillars that is respect for employees.

\section{Conflicts of Interest}

The authors declare no conflicts of interest regarding the publication of this paper.

\section{References}

[1] Mostafa, S. and Dumrak, J. (2020) A Waste Elimination Process: An Approach for Lean and Sustainable Manufacturing Systems. In: Management Association I, Ed., Sustainable Business: Concepts, Methodologies, Tools, and Applications, IGI Global, London, 567-598. https://doi.org/10.4018/978-1-5225-9615-8.ch026

[2] Womack, J.P., Jones, D.T. and Roos, D. (1990) The Machine That Changed the World. Massachusetts Institute of Technology, Cambridge.

[3] Chiarini, A., Baccarani, C. and Mascherpa, V. (2018) Lean Production, Toyota Production System and Kaizen Philosophy: A Conceptual Analysis from the Perspective of Zen Buddhism. The TQM Journal, 30, 425-438.

https://doi.org/10.1108/TQM-12-2017-0178

[4] Liker, J.K. (2004) The Toyota Way. McGraw Hill, New York.

[5] Arunagiri, P. and Gnanavelbabu, A. (2016) Identification of Major Leanwaste and Its Contributing Factors Using the Fuzzy Analytical Hierarchy Process. Transactions-Canadian Society for Mechanical Engineering, 40, 371-382. https://doi.org/10.1139/tcsme-2016-0027

[6] Ohno, T. and Bodek, N. (1988) Toyota Production System: Beyond Large-Scale Production. Productivity Press, New York.

[7] Holweg, M. (2007) The Genealogy of Lean Production. Journal of Operations Management, 25, 420-437. https://doi.org/10.1016/j.jom.2006.04.001

[8] Dalton, J. (2019) Gemba Walks. In: Great Big Agile, Apress, Berkeley, 173-174. https://doi.org/10.1007/978-1-4842-4206-3

[9] Vidyasagar, A. (2016) Best of Back to Basics: The Art of Root Cause Analysis. Quality Progress, 49, 48.

[10] Coetzee, R., van der Merwe, K. and van Dyk, L. (2016) Lean Implementation Strategies: How Are the Toyota Way Principles Addressed? South African Journal of Industrial Engineering, 27, 79-91. https://doi.org/10.7166/27-3-1641 
[11] Marin-Garcia, J.A., Juarez-Tarraga, A. and Santandreu-Mascarell, C. (2018) Kaizen Philosophy: The Keys of the Permanent Suggestion Systems Analyzed from the Workers' Perspective. The TQM Journal, 30, 296-320. https://doi.org/10.1108/TQM-12-2017-0176

[12] Sethi, R., Yanamadala, V., Burton, D.C. and Bess, R.S. (2017) Using Lean Process Improvement to Enhance Safety and Value in Orthopaedic Surgery: The Case of Spine Surgery. Journal of the American Academy of Orthopaedic Surgeons, 25, e244-e250. https://doi.org/10.5435/JAAOS-D-17-00030

[13] Bonaccorsi, A., Carmignani, G. and Zammori, F. (2011) Service Value Stream Management (SVSM): Developing Lean Thinking in the Service Industry. Journal of Service Science and Management, 4, 428-439. https://doi.org/10.4236/jssm.2011.44048

[14] Reason, J. (1990) Human Error. Cambridge University Press, Cambridge.

[15] Zhang, J.Q., Chen, X.B. and Sun, Q.B. (2019) A Safety Performance Assessment Framework for the Petroleum Industry's Sustainable Development Based on FAHP-FCE and Human Factors. Sustainability, 11, 1-20. https://doi.org/10.3390/su11133564

[16] Howell, G., Ballard, G. and Demirkesen, S. (2017) Why Lean Projects Are Safer. Proceedings of the 25th Annual Conference of the International Group for Lean Construction (IGLC), Volume II, Greece, 9-12 July 2017, 895-901. https://doi.org/10.24928/2017/0116

[17] Moaveni, S., Banihashemi, S.Y. and Mojtahedi, M. (2019) A Conceptual Model for a Safety-Based Theory of Lean Construction. Buildings, 9, Article No. 23. https://doi.org/10.3390/buildings9010023

[18] Karakhan, A.A. (2016) Designer's Liability: Why Applying PTD Principles Is Necessary. Professional Safety, 61, 53.

[19] Gambatese, J.A., Pestana, C. and Woo Lee, H. (2016) Alignment between Lean Principles and Practices and Worker Safety Behavior. Journal of Construction Engineering and Management, 143, Article ID: 4016083. https://doi.org/10.1061/(ASCE)CO.1943-7862.0001209

[20] Camuffo, A., De Stefano, F. and Paolino, C. (2017) Safety Reloaded: Lean Operations and High Involvement Work Practices for Sustainable Workplaces. Journal of Business Ethics, 143, 245-259. https://doi.org/10.1007/s10551-015-2590-8

[21] Jilcha, K. and Kitaw, D. (2016) Lean Influence on Occupational Safety and Health in Manufacturing Industries. Global Journal of Research in Engineering, 16, 1.

[22] Srinivasan, S., Ikuma, L.H., Shakouri, M., Nahmens, I. and Harvey, C. (2016) 5S Impact on Safety Climate of Manufacturing Workers. Journal of Manufacturing Technology Management, 27, 364-378. https://doi.org/10.1108/JMTM-07-2015-0053

[23] Blackmore, C.C., Bishop, R., Luker, S. and Williams, B.L. (2013) Applying Lean Methods to Improve Quality and Safety in Surgical Sterile Instrument Processing. The Joint Commission Journal on Quality and Patient Safety, 39, 99-105. https://doi.org/10.1016/S1553-7250(13)39014-X

[24] Cordeiro, P., Sá, J.C., Pata, A., Gonçalves, M., Santos, G. and Silva, F.J.G. (2020) The Impact of Lean Tools on Safety-Case Study. In: Arezes, P., et al., Eds., Occupational and Environmental Safety and Health II, Studies in Systems, Decision and Control, Vol. 277, Springer, Cham, 151-159.

[25] Fillingham, D. (2007) Can Lean Save Lives? Leadership in Health Services, 20, 231-241. 
https://doi.org/10.1108/17511870710829346

[26] Demirkesen, S. (2020) Measuring Impact of Lean Implementation on Construction Safety Performance: A Structural Equation Model. Production Planning \& Control, 31, 412-433. https://doi.org/10.1080/09537287.2019.1675914

[27] Bajjou, M.S., Chafi, A. and En-Nadi, A. (2017) The Potential Effectiveness of Lean Construction Tools in Promoting Safety on Construction Sites. International Journal of Engineering Research in Africa, 33, 179-193. https://doi.org/10.4028/www.scientific.net/JERA.33.179

[28] Ahmad, W., Rezaei, J., Tavasszy, L.A. and de Brito, M.P. (2016) Commitment to and Preparedness for Sustainable Supply Chain Management in the Oil and Gas Industry. Journal of Environmental Management, 180, 202-213. https://doi.org/10.1016/j.jenvman.2016.04.056

[29] European Commission (2019) Best Available Techniques Guidance Document on Upstream Hydrocarbon Exploration and Production. Final Guidance Document-Contract No. 070201/2015/706065/SER/ENV.F.1.

[30] Hovda, S., Wolter, H., Kaasa, G.-O. and Olberg, T.S. (2008) Potential of Ultra-High-Speed Drill String Telemetry in Future Improvements of the Drilling Process Control. SPE-115196-MS IADC/ SPE Asia Pacific Drilling Technology Conference and Exhibition, Jakarta, 25-27 August 2008. https://doi.org/10.2118/115196-MS

[31] Rehm, B., Schubert, J., Haghshenas, A., Paknejad, A.S. and Hughes, J. (2013) Managed Pressure Drilling. Elsevier, Amsterdam.

[32] Cullen, W.D. (1990) The Public Inquiry into the Piper Alpha Disaster. HMSO, London.

[33] Jernelöv, A. (2010) The Threats from Oil Spills: Now, Then, and in the Future. Ambio, 39, 353-366. https://doi.org/10.1007/s13280-010-0085-5

[34] Thiyagarajan, G. and Belayneh, M. (2018) Gap Analysis between Macondo Deep Water Horizon Drilling Blowout with Regulations and Industry Standards \& Codes. International Journal of Engineering Research and Technology, 11, 91-104.

[35] Deepwater Horizon Study Group (DHSG) Environmental Report (2011) The Macondo Blowout Environmental Report.

[36] Pickrell, B.D. and Bea, R.G. (1997) Assessment of Human \& Organizational Factors in Operations of Marine Terminals and Offshore Platforms. Department of Civil and Environmental Engineering University of California, Berkeley.

[37] Bea, R.G. (1998) Human and Organization Factors: Engineering Operating Safety into Offshore Structures. Reliability Engineering and System Safety, 61, 109-126. https://doi.org/10.1016/S0951-8320(97)00058-6

[38] Ratnayake, R.M.C. and Markeset, T. (2010) Maintaining Technical Integrity of Petroleum Flowlines on Offshore Installations: A Decision Support System for Inspection Planning. Proceedings of the ASME 2010 29th International Conference on Ocean, Offshore and Arctic Engineering, Volume 6, Shanghai, 6-11 June 2010, 1-11. https://doi.org/10.1115/OMAE2010-20035

[39] Lim, J.S., Kueh, J.Z. and Maskawi, B. (2019) Improvement of Operational Excellence: Reducing Unplanned Production Deferment. Society of Petroleum Engineers, London.

[40] Laing, T., Upadhyay, A., Mohan, S. and Subramanian, N. (2019) Environmental Improvement Initiatives in the Coal Mining Industry: Maximisation of the Triple Bottom Line. Production Planning \& Control, 30, 426-436. 
https://doi.org/10.1080/09537287.2018.1501813

[41] Manuele, F.A. (2005) Risk Assessment \& Hierarchies of Control: Their Growing Importance to the SH\&E Profession. American Society of Safety Professionals-Safety Management, 50, 33-39.

[42] Dodoo, J.E. and Al-Samarraie, H. (2019) Factors Leading to Unsafe Behavior in the Twenty First Century Workplace: A Review. Management Review Quarterly, 69, 391-414. https://doi.org/10.1007/s11301-019-00157-6

[43] Longwell, H.J. (2002) The Future of the Oil and Gas Industry: Past Approaches, New Challenges. World Energy, 5, 100-104.

[44] Dewardt, J.P. (1995) Lean Drilling-Introducing the Application of Automotive Lean Manufacturing Techniques to Well Construction. Journal of Petroleum Technology, 47, 113-114.

[45] Abimbola, M., Khan, F. and Khakzad, N. (2016) Risk-Based Safety Analysis of Well Integrity Operations. Safety Science, 84, 149-160.

https://doi.org/10.1016/j.ssci.2015.12.009

[46] Vignes, B., Safety, P. and Aadnoy, B.S. (2008) Well-Integrity Issues Offshore Norway. IADC/ SPE Drilling Conference, Orlando, 4-6 March 2008, 91-119. https://doi.org/10.2118/112535-MS

[47] Torbergsen, H.-E.B., Norge, E., Haga, H.B., et al. (2012) An Introduction to Well Integrity.

[48] Favilla, J.R., Claessens, D.A., Mello, U. and Flach, B. (2012) Achieving Excellence in E\&P Offshore Logistics. SPE Intelligent Energy International, Utrecht, March 2012, SPE-150396-MS. https://doi.org/10.2118/150396-MS

[49] Wilson, J.U. and Odesola, I.A. (2017) Design-Related Causes of Rework and the Performance of Oil and Gas Projects in Nigeria. International Journal of Sustainable Construction Engineering \& Technology, 8, 60-76.

[50] Goshime, Y., Kitaw, D. and Jilcha, K. (2019) Lean Manufacturing as a Vehicle for Improving Productivity and Customer Satisfaction: A Literature Review on Metals and Engineering Industries. International Journal of Lean Six Sigma, 10, 691-714. https://doi.org/10.1108/IJLSS-06-2017-0063

[51] Kilpatrick, J. (2003) Lean Principles. Utah Manufacturing Extension Partnership. Orem, UT. (Google Scholar)

[52] Farshad, A., Khosravi, Y. and Alizadeh, S. (2006) The Role of HSE Management System in Improving Health, Safety and Environment Performance in an Oil Organization.

[53] Buell, R.S. (2006) Creating a Culture to Deliver Sustainable HSE Performance. Society of Petroleum Engineers, London. https://doi.org/10.2118/98564-MS

[54] Bellarby, J. (2009) Well Completion Design. Developments in Petroleum Science, $56,668-674$.

[55] Inderberg, O. and Neuenkirchen, J.-H. (2010) Presentation on Theme: Well Integrity Round Table Discussion Washington. Well Integrity Round Table Discussion Washington 2010. (slideplayer.com)

[56] Deming, W.E. (1986) Out of the Crisis. MIT Centre for Advanced Engineering, Cambridge.

[57] OGUK (2019) Health and Safety Report. The UK Oil and Gas Industry Association Limited (trading as OGUK) 2019, 1-52.

https://oguk.org.uk/product/economic-report/ 